\title{
ADENSAMENTO DE PLANTAS E ÉPOCAS DE CULTIVO DE SOJA EM CONDIÇÕES DE CERRADO
}

Eduardo Lima do Carmo, Antonio Germano Carpim Rocha, Gustavo André Simon, Alessandro Guerra da Silva, Guilherme Braga Pereira Braz

Universidade de Rio Verde - UniRV, Curso de Agronomia, Rio Verde, GO. E-mail: guilhermebrag@gmail.com

\section{RESUMO}

A distribuição de plantas de soja, bem como sua conjunção à determinada época de semeadura pode resultar em melhor aproveitamento da área de cultivo e, consequentemente, influenciar de maneira positiva o rendimento de grãos. Nesse âmbito, o objetivo deste trabalho foi avaliar o desempenho agronômico de cultivares de soja em espaçamento entrelinhas adensado e esse procedimento associado a épocas de semeadura distintas. Para tanto, foram realizados três ensaios de campo em duas safras agrícolas. Na safra 2014/15 foi conduzido experimento em delineamento de blocos casualizados, com 4 repetições, em arranjo fatorial $8 \times 2$. Os tratamentos foram constituídos pela combinação de oito cultivares de soja e dois espaçamentos entrelinhas de semeadura: tradicional e adensado $(0,5$ e $0,25 \mathrm{~m}$, respectivamente). Na safra seguinte (2015/16), foram realizados dois experimentos, cada um com uma cultivar de soja. Utilizou-se o mesmo delineamento e quantidade de repetições, diferindo-se do experimento anterior devido à adoção de esquema de parcelas subdivididas. Nas parcelas foram alocadas três épocas de semeadura equidistantes em 15 dias, e nas subparcelas foram dispostos os espaçamentos tradicional e adensado de semeadura. Não houve diferença entre os espaçamentos entrelinhas de semeadura utilizados no experimento realizado na primeira safra, observando variação apenas entre as cultivares de soja. Cultivares com ciclo mais longo apresentam maiores produtividades. Para os experimentos realizados na segunda safra, foi verificado maior efeito das épocas de semeadura em relação ao espaçamento entrelinhas, observando maiores produtividades da soja nas semeaduras realizadas mais precocemente.

Palavras-chave: arranjo de plantas; componentes do rendimento; espaçamento reduzido; plasticidade fenotípica

\section{PLANT DENSIFICATION AND SOYBEAN SOWING PERIOD IN CERRADO CONDITIONS}

\begin{abstract}
The distribution of soybean plants, as well as the conjunction to a determined sowing date can result in better use of the growing area and, consequently, influence in a positive way the grain yield. In this context, the objective of this work was to evaluate the agronomic performance of soybean cultivars in narrow row and this procedure associated to different sowing dates. Therefore, three field experiments were performed in two agriculture seasons. In the season 2014/15 an experiment was conducted in randomized completely block design, with four repetitions, in factorial arrangement $8 \times 2$. The combination of eight soybean cultivars and two spacing sowing between rows, traditional and narrow $(0.5$ and $0.25 \mathrm{~m}$, respectively), composed the treatments. In the following season (2015/16), two experiment were performed, each one with a soybean cultivar. The same experimental design and number of repetition was used, differing from the anterior experiment by the adoption of split plot scheme. The three sowing dates, equidistant in 15 days, were allocated in the plots, and disposing in the subplots the traditional and narrow sowing spacing. There was no difference between spacing row used in the experiment performed in the first season, observing variation only among the soybean cultivars. Cultivars with longer crop cycle showed the greatest yields. For the experiments performed in the second season, it was verified higher effect of sowing date in relation to the spacing between rows, observing greatest soybean yields in the earliest sowing date.
\end{abstract}

Keywords: plants spatial arrangements; yield components; narrow rows; phenotypic plasticity 


\section{INTRODUÇÃO}

A produtividade de grãos na cultura da soja tem relação direta com vários fatores, entre os quais podem ser elencados o arranjo espacial de plantas, época de semeadura, genótipos implantados e condições climáticas. $O$ arranjo espacial é definido como a forma em que plantas se encontram distribuídas na área de cultivo e, esse fator está implicitamente associado à competição, intrínseca ou não, pela utilização dos recursos disponíveis (MUNDSTOCK; THOMAS, 2005).

No âmbito do arranjo espacial de plantas, uma das formas de se alterar o manejo da cultura está na adoção de espaçamento entrelinhas mais adensados, o qual poderá influenciar o fechamento da cultura, rendimento de biomassa, ramificação, severidade de doenças, acamamento de plantas e produtividade (BALBINOT JÚNIOR, 2011; COX; CHERNEY, 2011; LIMA et al., 2012; SILVA et al., 2013).

Trabalhos sobre $\mathrm{o}$ adensamento de semeadura na soja, em geral, demonstram que cultivares precoces e de estatura menor apresentam melhor desempenho agronômico quando comparadas com as de ciclo tardio e porte mais elevado. Isto é explicado pelo fato de essas, normalmente, apresentarem maior número de ramificações e folíolos de maior tamanho, o que confere maior capacidade fotossintética (WALKER et al., 2010).

A época de cultivo, por sua vez, é fundamental para produtividade de uma cultura, pois resulta em alterações das relações hídricas, bem como, temperatura, fotoperíodo e radiação solar disponíveis à planta (SUBEDI et al., 2007). A semeadura em períodos inadequados pode refletir diretamente no rendimento final da cultura prejudicando, por exemplo, a colheita mecanizada com elevação das perdas em virtude da altura de plantas e de inserção de primeira vagem, número de ramificações e acamamento, uma vez que na maioria dos trabalhos realizados há relato de perda de rendimento de grãos com o atraso da semeadura (PELUZIO et al., 2010).
Outro fator preponderante para a definição do arranjo de plantas na área e época em que será realizada a semeadura é a escolha da cultivar de soja, tendo em vista que alguns genótipos respondem ao adensamento e outros não (DUTRA et al., 2007). Apesar disso, tendo em vista o grande número de cultivares de soja disponíveis no mercado agrícola, são escassos os registros que avaliem a interação entre a distribuição espacial de plantas e a época de cultivo, dado que essa informação, para determinada região e cultivar a ser implantada, pode auxiliar o produtor rural na tomada de decisão e na continuidade da atividade agrícola.

O objetivo deste trabalho foi avaliar a performance de genótipos de soja em espaçamento entrelinhas de semeadura adensado, assim como essa técnica associada à diferentes épocas de semeadura.

\section{MATERIAL E MÉTODOS}

O trabalho foi realizado a campo na fazenda experimental da Universidade de Rio Verde ( $17^{\circ} 47^{\prime} 53^{\prime \prime}$ S; $51^{\circ} 55^{\prime} 53^{\prime \prime}$ W e $756 \mathrm{~m}$ de altitude), localizada no município de Rio Verde (GO). Os experimentos foram conduzidos nas safras agrícolas de 2014/15 e 2015/16.

0 solo da área experimental foi classificado como Latossolo Vermelho distroférrico (EMBRAPA, 2013), apresentando histórico de cultivo em sistema de plantio direto tendo como cultura antecessora o milho. Em análise de solo da área experimental, este apresentou as seguintes características: $24,9 \mathrm{~g}$ $\mathrm{dm}^{-3}$ de M.O, 5,4 de $\mathrm{pH}$ em $\mathrm{CaCl}_{2} ; 5,5 \mathrm{mg} \mathrm{dm}^{-3}$ de P; $0,51 \mathrm{cmol}_{\mathrm{c}} \mathrm{dm}^{-3}$ de K; $3,18 \mathrm{cmol}_{\mathrm{c}} \mathrm{dm}^{-3}$ de Ca; $1,52 \mathrm{cmol}_{\mathrm{c}} \mathrm{dm}^{-3}$ de $\mathrm{Mg} ; 51,29 \%$ de saturação de bases (V\%).

Segundo a classificação de Köppen, o clima para a localidade é do tipo Aw, que recebe o nome de clima tropical com estação seca, caracterizado por apresentar chuvas mais intensas no verão em comparação ao inverno. Dados de precipitação e temperatura média do ar, durante a condução dos ensaios, estão apresentados na Figura 1. 
Figura 1. Precipitação pluvial e temperatura média do ar em Rio Verde (GO) durante as safras de verão compreendidas entre os anos de 2014 a 2016.

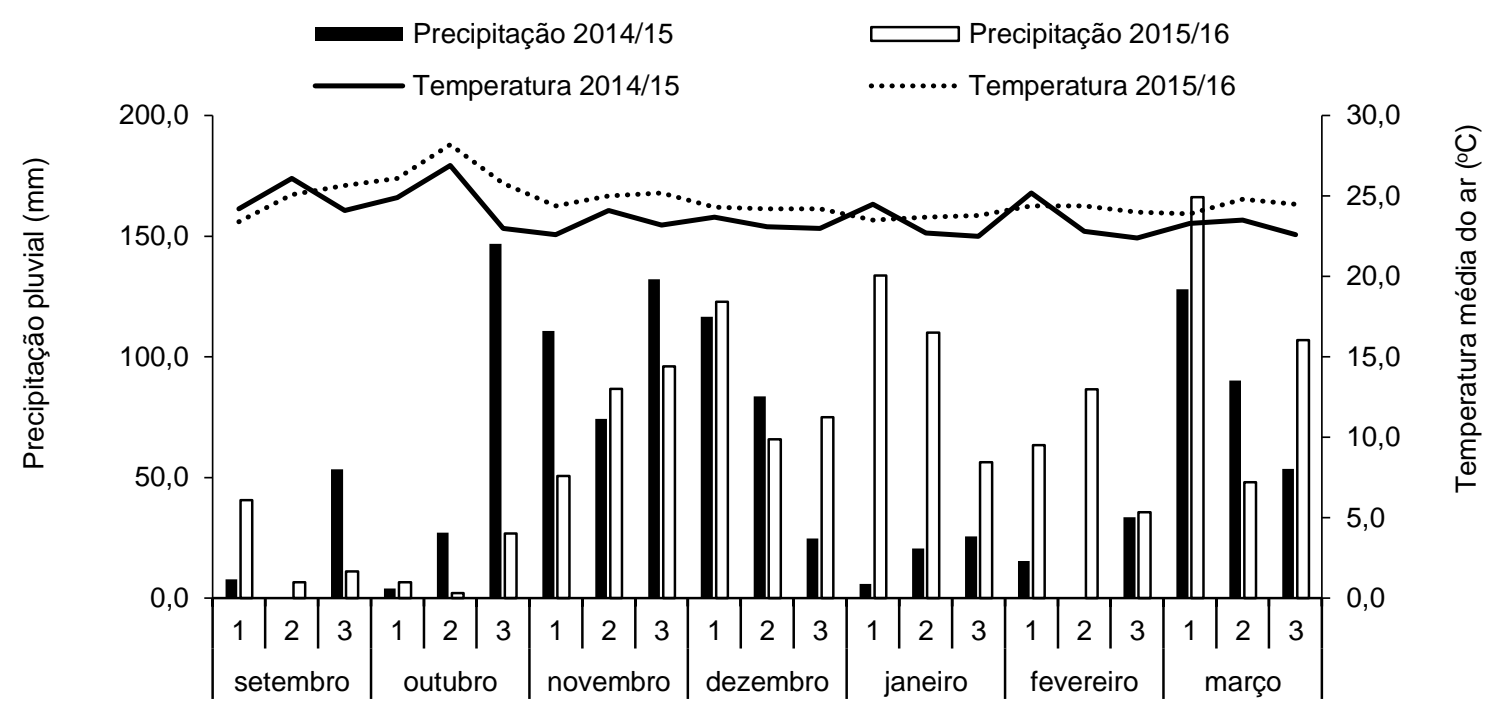

Meses (decêndios)

\section{Adensamento e cultivares de soja (Safra 2014/15)}

Na primeira safra (2014/2015), instalouse o experimento no dia 29 de outubro de 2014, o qual foi conduzido em delineamento de blocos completamente casualizados com 4 repetições em esquema fatorial $8 \times 2$. 0 primeiro fator avaliado foi constituído por oito cultivares de soja, utilizando como critério de escolha das mesmas à abrangência regional de cultivo que possuem. Na Tabela 1 estão apresentadas as cultivares e suas principais características, juntamente com a população em que foram semeadas. O segundo fator correspondeu a semeadura da soja em dois espaçamentos entrelinhas, compostos pelo tradicional e adensado, 0,5 e 0,25 m, respectivamente.

As unidades experimentas possuíram dimensões de $5 \mathrm{~m}$ de comprimento por $3,5 \mathrm{~m}$ de largura, totalizando área bruta de $17,5 \mathrm{~m}^{2}$. A área útil na qual foram realizadas as avaliações apresentou $6 \mathrm{~m}^{2}$ (3 m de comprimento por $2 \mathrm{~m}$ de largura).

Tabela 1. Relação de cultivares de soja avaliadas no experimento de adensamento de plantas. Rio Verde (GO)

\begin{tabular}{lccc}
\hline \multicolumn{1}{c}{ Cultivar } & População $\left(\text { plantas ha }{ }^{-1}\right)^{*}$ & Hábito de crescimento $^{*}$ & Grupo de maturação $^{*}$ \\
\hline BMX Desafio RR $^{\circ}$ & 360.000 & Indeterminado & 7.4 \\
BMX Potência RR & 400.000 & Indeterminado & 6.7 \\
BMX Raça RR $^{\circ}$ & 300.000 & Indeterminado & 7.6 \\
NA 5909 RR & 440.000 & Indeterminado & 6.9 \\
NS 7670 RR & 320.000 & Indeterminado & 7.6 \\
W 791 RR & 280.000 & Indeterminado & 7.6 \\
M 7739 IPRO & 280.000 & Semideterminado & 7.7 \\
Anta 82 RR & 500.000 & Semideterminado & 7.4 \\
\hline
\end{tabular}

* Informações adquiridas no catálogo de cultivares das respectivas empresas detentoras.

Adensamento e épocas de semeadura (Safra 2015/16)
$\mathrm{Na}$ segunda safra (2015/16), foram conduzidos dois experimentos, nos quais utilizou- 
se duas cultivares de soja distintas, sendo utilizadas a M 7739 IPRO $^{\circ}$ e a NA 5909 RR ${ }^{\circ}$. O delineamento experimental utilizado em ambos os experimentos foi o de blocos ao acaso, em esquema de parcelas subdivididas, com 4 repetições. Nas parcelas foram alocadas 3 épocas de semeadura, equidistantes em 15 dias a partir de 18 de outubro e, nas subparcelas foram dispostos, aleatoriamente, os dois espaçamentos de semeadura: tradicional $(0,5 \mathrm{~m})$ e adensado $(0,25 \mathrm{~m})$.

As parcelas constituíram-se de $11 \mathrm{~m}$ de comprimento por $2 \mathrm{~m}$ de largura com um corredor central de $1 \mathrm{~m}$, o qual separava as subparcelas, totalizando uma área de $22 \mathrm{~m}^{2}$. A área útil foi obtida com duas e quatro linhas centrais para os respectivos formatos de semeadura, desconsiderando $1 \mathrm{~m}$ de cada extremidade, perfazendo $3 \mathrm{~m}^{2}$ por subparcela.

As cultivares de soja utilizadas foram NA $5909 \mathrm{RR}^{\circ}$ e M 7739 IPRO $^{\circ}$. Ambas escolhidas devido ao expressivo cultivo de áreas comerciais da região Sudoeste de Goiás. Á semeadura foi realizada almejando se obter a mesma população de plantas utilizada na Tabela 1 para cada cultivar de soja.

Em ambas as safras e ensaios, dez dias anteriores às semeaduras, dessecou-se as plantas daninhas presentes nas áreas via pulverizador montado com aplicação do herbicida glifosato (1200 g e.a. ha $\left.{ }^{-1}\right)$. As sementes foram tratadas com thiametoxam; fipronil + piraclostrobina + tiofanato-metílico $(105 ; 60+6+54$ g i.a., respectivamente, para $100 \mathrm{~kg}$ de sementes) e inoculante líquido composto das estirpes Semia 5079 e 5080 em concentração de $6 \times 10^{-9}$ unidades formadoras de colônia na proporção de $50 \mathrm{~mL}$ para $50 \mathrm{~kg}$ de sementes.

As semeaduras foram efetuadas por semeadora-adubadora com mecanismo cônico de distribuição contínua de sementes, equipada com 7 discos duplos excêntricos, espaçados de $0,25 \mathrm{~m}$. A adubação de base resultou da aplicação antecipada (7 dias) de 3 toneladas por hectare de cama de aviário de corte (8o lote) e, na ocasião da semeadura foram aplicados, via haste sulcadora, $300 \mathrm{~kg}$ do adubo formulado 02-20-18 (NPK) e, 15 dias após, $100 \mathrm{~kg} \mathrm{ha}^{-1}$ de cloreto de potássio a lanço.

Após 10 dias da emergência das plantas, efetuou-se desbaste manual de forma estabelecer a distribuição espacial desejada de cada tratamento. Os tratos culturais referentes ao controle de plantas daninhas, pragas e doenças foram efetuados conforme necessidade técnica da cultura por meio de aplicação terrestre em taxa de $150 \mathrm{~L} \mathrm{ha}^{-1}$.

$\mathrm{Na}$ colheita, foram realizadas as seguintes avaliações na área útil das parcelas em quinze plantas contínuas: alturas de plantas e de inserção da primeira vagem (medida do solo até a extremidade do último racemo floral e de inserção do primeiro legume, respectivamente); número de ramificações, de vagens por planta e de grãos por vagem, massa de mil grãos (pesagem de mil grãos, com correção da umidade para 13\%); e produtividade de grãos (colheita e trilha das plantas da área útil, com posterior pesagem dos grãos e correção da umidade para $13 \%)$.

As análises estatísticas foram realizadas com o programa computacional Sisvar (FERREIRA, 2011). Os dados obtidos na primeira safra (2014/15) foram submetidos à análise de variância, e quando constatado efeito significativo, empregou-se o teste de Scott-Knott a $5 \%$ de probabilidade. Para os experimentos conduzidos na segunda safra (2015/16), constatado efeito significativo dos tratamentos, as médias foram comparadas pelo teste de Tukey a $5 \%$ de probabilidade.

A utilização de diferentes testes de comparação de médias para cada safra está relacionada ao número de tratamentos avaliados nos experimentos. No experimento realizado na primeira safra havia uma quantidade maior de tratamentos, e por isso optou-se pela utilização do teste de Scott-Knott, devido ao fato do mesmo não apresentar ambiguidade (Silva et al., 1999). Para os experimentos conduzidos na segunda safra, havia menor quantidade de tratamentos, optando-se pela utilização do teste de Tukey.

\section{RESULTADOS E DISCUSSÃO}

\section{Adensamento e cultivares de soja (Safra 2014/15)}

Na primeira safra (2014/15), houve influência dos genótipos cultivados em todas as variáveis-respostas analisadas (Tabela 2). Não foi observado efeito significativo do espaçamento entrelinhas ou da interação entre esse fator e as cultivares de soja. 
Tabela 2. Resumo da análise de variância (valores de $f$ calculado) de características morfológicas, componentes do rendimento e produtividade de grãos de genótipos de soja cultivados em diferentes espaçamentos entrelinhas de semeadura na safra de verão. Rio Verde (GO), 2014/15

\begin{tabular}{lcccccccc}
\hline \multicolumn{1}{c}{ Fontes de variação } & $\mathrm{GL}$ & $\mathrm{ALP}$ & $\mathrm{APV}$ & $\mathrm{RAM}$ & $\mathrm{NVP}$ & $\mathrm{NGV}$ & $\mathrm{MMG}$ & $\mathrm{PRO}$ \\
\hline Cultivar (C) & 7 & $15,7^{* *}$ & $4,9^{* *}$ & $23,4^{* *}$ & $19,0^{* *}$ & $15,8^{* *}$ & $12,1^{* *}$ & $2,6^{*}$ \\
Espaçamento (E) & 1 & $0,5^{\text {ns }}$ & $0,0^{\text {ns }}$ & $0,6^{\text {ns }}$ & $1,7^{\text {ns }}$ & $0,0^{\text {ns }}$ & $0,0^{\text {ns }}$ & $3,1^{\text {ns }}$ \\
C X E & 7 & $1,1^{\text {ns }}$ & $1,0^{\text {ns }}$ & $0,7^{\text {ns }}$ & $0,3^{\text {ns }}$ & $1,1^{\text {ns }}$ & $1,1^{\text {ns }}$ & $0,5^{\text {ns }}$ \\
Erro & 45 & - & - & - & - & - & - & - \\
CV (\%) & & 8,2 & 24,7 & 27,7 & 18,3 & 6,2 & 6,5 & 14,7 \\
\hline
\end{tabular}

$\mathrm{ALP}=$ altura de plantas; $\mathrm{APV}=$ altura de inserção da primeira vagem; $\mathrm{RAM}=$ número de ramificações por planta; $\mathrm{NVP}=$ número de vagens por planta; $N G V=$ número de grãos por vagem; $M M G=$ massa de mil grãos; $P R O=$ produtividade. ${ }^{\text {ns }}$ Não significativo. **, * Significativo a 1 e $5 \%$ de probabilidade pelo Teste de $\mathrm{F}$, respectivamente.

As maiores alturas de plantas foram encontradas para as cultivares BMX Potência RR', BMX Raça RR', W 791 RR $^{\circ}$ e Anta 82 RR $^{\circ}$ (Tabela 3). Em trabalhos de arranjo de plantas, geralmente, observa-se efeito da população e da cultivar sobre essa variável (altura de plantas), com ausência de significância para o espaçamento entrelinhas (PRICINOTTO; ZUCARELI, 2014; BALBINOT JÚNIOR et al., 2015).
Ao analisar os resultados para as cultivares BMX Potência RR ${ }^{\circ}$ e Anta $82 R^{\circ}{ }^{\circ}$, o fato de se observar plantas com porte mais elevado pode estar relacionado ao número de plantas por área (população). Isso se explica pelo fato de que com o acréscimo da densidade de semeadura, aumenta a competição intraespecífica por luz, ocasionando o estiolamento das plantas de soja (MAUAD et al., 2010).

Tabela 3. Valores médios de características morfológicas e componente de rendimento de genótipos de soja cultivados em diferentes espaçamentos entrelinhas de semeadura na safra de verão. Rio Verde (GO), $2014 / 15$

\begin{tabular}{|c|c|c|c|c|c|c|}
\hline \multirow{2}{*}{ Cultivares } & \multicolumn{3}{|c|}{--- Altura de plantas $(\mathrm{cm})$--- } & \multicolumn{3}{|c|}{--- Altura de inserção da $1^{\text {ạ }}$ vagem $(\mathrm{cm})$-- } \\
\hline & Tradicional & Adensado & Média & Tradicional & Adensado & Média \\
\hline BMX Desafio RR $^{\circ}$ & 63,1 & 60,3 & $61,7 c^{*}$ & 14,1 & 12,8 & $13,4 \mathrm{~b}$ \\
\hline BMX Potência RR ${ }^{\circledR}$ & 69,8 & 77,6 & $73,7 \mathrm{a}$ & 9,1 & 9,8 & $9,5 \mathrm{~b}$ \\
\hline BMX Raça RR ${ }^{\circledR}$ & 78,6 & 76,5 & 77,6 a & 18,2 & 17,1 & 17,6 a \\
\hline NA $5909 R^{\circ}$ & 55,3 & 53,5 & $54,4 \mathrm{~d}$ & 12,7 & 10,5 & $11,6 \mathrm{~b}$ \\
\hline NS $7670 \mathrm{RR}^{\circ}$ & 69,5 & 67,5 & $68,5 \mathrm{~b}$ & 14,4 & 13,0 & $13,7 \mathrm{~b}$ \\
\hline W 791 RR $^{\circ}$ & 80,2 & 73,6 & $76,9 a$ & 15,5 & 14,3 & $14,9 \mathrm{a}$ \\
\hline M 7739 IPRO $^{\circ}$ & 68,5 & 70,7 & $69,6 \mathrm{~b}$ & 14,1 & 18,7 & $16,4 \mathrm{a}$ \\
\hline Anta $82 \mathrm{RR}^{\circ}$ & 76,0 & 73,0 & $74,5 \mathrm{a}$ & 10,9 & 13,3 & $12,1 \mathrm{~b}$ \\
\hline \multirow[t]{3}{*}{ Média } & 70,1 & 69,1 & & 13,6 & 13,7 & \\
\hline & \multicolumn{3}{|c|}{--- Número de ramificações por planta } & \multicolumn{3}{|c|}{--- Número de vagens por planta --- } \\
\hline & Tradicional & Adensado & Média & Tradicional & Adensado & Média \\
\hline BMX Desafio RR & 2,1 & 2,2 & $2,2 \mathrm{c}$ & 40,8 & 40,0 & $40,4 \mathrm{~b}$ \\
\hline BMX Potência $\mathrm{RR}^{\circ}$ & 2,2 & 2,0 & $2,1 \mathrm{c}$ & 29,7 & 30,8 & $30,3 \mathrm{c}$ \\
\hline BMX Raça RR & 4,7 & 4,4 & $4,5 \mathrm{a}$ & 42,5 & 41,0 & $41,8 \mathrm{~b}$ \\
\hline NA $5909 R^{\circ}$ & 3,2 & 3,5 & $3,3 \mathrm{~b}$ & 27,2 & 29,6 & $28,4 \mathrm{c}$ \\
\hline NS $7670 R^{\circ}$ & 2,3 & 2,3 & $2,3 \mathrm{c}$ & 53,4 & 58,3 & $55,8 \mathrm{a}$ \\
\hline W 791 RR $^{\circ}$ & 2,4 & 2,3 & $2,3 \mathrm{c}$ & 56,9 & 60,6 & 58,8 a \\
\hline M 7739 IPRO $^{\circ}$ & 4,6 & 5,8 & $5,2 \mathrm{a}$ & 40,7 & 48,9 & $44,8 \mathrm{~b}$ \\
\hline Anta $82 \mathrm{RR}^{\circ}$ & 1,0 & 1,3 & $1,1 \mathrm{~d}$ & 29,3 & 30,8 & $30,1 \mathrm{c}$ \\
\hline Média & 2,8 & 3,0 & & 40,1 & 42,5 & \\
\hline
\end{tabular}

* Médias seguidas de letras iguais, na linha, não se diferem pelo teste de Scott-Knott a 5\% de probabilidade. 
Apesar de haver tendência de ocorrer estiolamento das plantas de soja quando semeadas em densidades mais elevadas, a altura de plantas consiste em característica intrínseca para cada cultivar. Desta forma, para determinados materiais de soja, essa variável não é tão facilmente influenciada pelas práticas adotadas no manejo da cultura. Tal relato pode ser observado para a cultivar NA 5909 RR $^{\circ}$ que, apesar de ter sido semeada em densidade consideravelmente alta, apresentou plantas com valores de altura inferior às demais.

As cultivares BMX Raça RR', W 791 RR $^{\circ}$ e M 7739 IPRO $^{\circ}$ apresentaram maiores alturas de inserção de primeira vagem (Tabela 3). Aparentemente, essa variável possui relação com a altura de plantas devido ao alongamento da haste, fato que pode ser observado para as cultivares BMX Raça RR ${ }^{\circ}$ e W 791 RR $^{\circ}$. Apesar de M7739 IPRO ${ }^{\circ}$ não se enquadrar nesse quesito, a explicação se restringe à ramificação. A campo, nota-se que essa cultivar ramifica-se um pouco acima do colo da planta, e o crescimento dessas estruturas, eleva a inserção da primeira vagem, que coincidentemente está posicionado em sua extensão, estando os legumes da haste principal localizado acima desse.

Reconhecer a altura de inserção de primeira vagem é importante para determinar a altura da barra de corte da colhedora, visando obter a máxima eficiência durante a colheita (MAUAD et al., 2010). Almeida et al. (2011), relataram que o cultivo de plantas muito altas (maiores que $80 \mathrm{~cm}$ ) e com baixa altura de inserção de primeira vagem (menores que $10 \mathrm{~cm}$ ) pode proporcionar perdas na colheita mecanizada da soja. Observando-se os valores médios de alturas de plantas e de inserção da primeira vagem das oito cultivares utilizadas neste experimento, nota-se que todas atenderam ao requisito indicado para se evitar perdas na colheita.

A capacidade de ramificação de uma cultivar não deve ser avaliada isoladamente, mas em conjunto com a produção de grãos provenientes desses ramos (PROCÓPIO et al., 2014). As cultivares $B M X$ Raça $R R^{\circ}$ e $M 7739$
$\mathrm{IPRO}^{\circ}$ foram superiores em números de ramificações e, consequentemente, em vagens laterais (Tabela 3 ).

O número de ramos por planta, comprimento de ramos e números de nós férteis, apresentam relação com o potencial produtivo da soja, uma vez que essas variáveis indicam maior superfície fotossintetizante e produtiva por meio do aumento do número de locais para desenvolvimento de gemas reprodutivas. Em contrapartida, aumento nos valores dessas variáveis representa demanda adicional para a planta, criando a necessidade de desvio de fotoassimilados para o desenvolvimento e manutenção das estruturas, os quais seriam aproveitados na fixação e produção de estruturas reprodutivas da soja (NAVARRO JÚNIOR; COSTA, 2002).

A análise dos componentes de rendimento da soja apresenta extrema importância, pois permite compreender como os tratamentos influenciaram a produtividade da cultura. Em relação ao número de vagens por planta, observou-se maiores valores para as cultivares NS 7670 RR $^{\circ}$ e W 791 RR $^{\circ}$ (Tabela 3). Um fato que merece destaque, e que pode ser avaliado em experimentos futuros, é a relação dessa variável-resposta com o ciclo das cultivares de soja, uma vez que se observou tendência de haver maior número de vagens por plantas nas cultivares que tiveram maior tempo de permanência no campo.

O maior número de vagens por planta na cultivar NS $7670 \mathrm{RR}^{\circ}$ refletiu em inferioridade quanto ao número de grãos por vagem, sendo a cultivar BMX Potência $\mathrm{RR}^{\circ}$ a que apresentou maiores valores para esta variável, sendo superior as demais cultivares avaliadas (Tabelas 3 e 4).

Em trabalho anterior apresentado na literatura, foi sugerido que os componentes do rendimento apresentam variações entre eles com efeitos de compensação, no sentido de uniformizar o rendimento de grãos, entre cultivares, densidades de plantas e épocas de semeadura (PEIXOTO et al., 2000). 
Tabela 4. Valores médios de componentes de rendimento e produtividade de genótipos de soja cultivados em diferentes espaçamentos entrelinhas de semeadura na safra de verão. Rio Verde (GO), 2014/15

\begin{tabular}{|c|c|c|c|c|c|c|}
\hline \multirow{2}{*}{ Cultivares } & \multicolumn{3}{|c|}{--- Número de grãos por vagem --- } & \multicolumn{3}{|c|}{--- Massa de 1000 grãos (g) --- } \\
\hline & Tradicional & Adensado & Média & Tradicional & Adensado & Média \\
\hline BMX Desafio RR ${ }^{\circ}$ & 2,5 & 2,5 & $2,5 b^{*}$ & 128 & 137 & $132 \mathrm{~b}$ \\
\hline BMX Potência RR ${ }^{\oplus}$ & 2,7 & 2,6 & $2,7 \mathrm{a}$ & 128 & 121 & $124 \mathrm{~b}$ \\
\hline BMX Raça RR ${ }^{\circ}$ & 2,4 & 2,4 & $2,4 \mathrm{~b}$ & 133 & 137 & $135 b$ \\
\hline NA $5909 R^{\circ}$ & 2,3 & 2,4 & $2,4 \mathrm{~b}$ & 136 & 131 & $134 \mathrm{~b}$ \\
\hline NS 7670 RR $^{\circ}$ & 1,9 & 2,0 & $1,9 \mathrm{c}$ & 152 & 148 & $150 \mathrm{a}$ \\
\hline W 791 RR $^{\circ}$ & 2,4 & 2,4 & $2,4 b$ & 129 & 132 & $130 \mathrm{~b}$ \\
\hline M 7739 IPRO & 2,3 & 2,2 & $2,3 \mathrm{~b}$ & 126 & 131 & $128 \mathrm{~b}$ \\
\hline Anta $82 \mathrm{RR}^{\circ}$ & 2,5 & 2,3 & $2,4 \mathrm{~b}$ & 117 & 109 & $113 \mathrm{c}$ \\
\hline \multirow[t]{3}{*}{ Média } & 2,4 & 2,4 & & 131 & 131 & \\
\hline & \multicolumn{6}{|c|}{--- Produtividade de grãos $\left(\mathrm{kg} \mathrm{ha}^{-1}\right)$--- } \\
\hline & \multicolumn{2}{|c|}{ Tradicional } & \multicolumn{2}{|c|}{ Adensado } & \multicolumn{2}{|c|}{ Média } \\
\hline BMX Desafio RR ${ }^{\circ}$ & \multicolumn{2}{|c|}{3571} & \multicolumn{2}{|r|}{4037} & \multicolumn{2}{|c|}{$3804 \mathrm{~b}$} \\
\hline BMX Potência RR ${ }^{\circ}$ & \multicolumn{2}{|c|}{3632} & \multicolumn{2}{|r|}{3970} & \multicolumn{2}{|c|}{$3801 \mathrm{~b}$} \\
\hline BMX Raça RR & \multicolumn{2}{|c|}{3823} & \multicolumn{2}{|r|}{3840} & \multicolumn{2}{|c|}{$3832 \mathrm{~b}$} \\
\hline NA $5909 R^{\circ}$ & \multicolumn{2}{|c|}{3426} & \multicolumn{2}{|r|}{3581} & \multicolumn{2}{|c|}{$3503 \mathrm{~b}$} \\
\hline NS $7670 \mathrm{RR}^{\circ}$ & \multicolumn{2}{|c|}{4082} & \multicolumn{2}{|r|}{4651} & \multicolumn{2}{|c|}{$4367 \mathrm{a}$} \\
\hline W 791 RR & \multicolumn{2}{|c|}{4346} & \multicolumn{2}{|r|}{4155} & \multicolumn{2}{|c|}{4251 a } \\
\hline M 7739 IPRO $^{\circ}$ & \multicolumn{2}{|c|}{3515} & \multicolumn{2}{|r|}{4073} & \multicolumn{2}{|c|}{$3794 \mathrm{~b}$} \\
\hline Anta $82 \mathrm{RR}^{\circ}$ & \multicolumn{2}{|c|}{3408} & \multicolumn{2}{|r|}{3489} & \multicolumn{2}{|c|}{$3448 \mathrm{~b}$} \\
\hline Média & \multicolumn{2}{|c|}{3725} & \multicolumn{2}{|r|}{3974} & & \\
\hline
\end{tabular}

* Médias seguidas de letras iguais, na linha, não se diferem pelo teste de Scott-Knott a 5\% de probabilidade.

A cultivar NS $7670 \mathrm{RR}^{\circ}$ apresentou maior valor de massa de mil grãos em relação às demais (Tabela 4). Entre os diferentes componentes de rendimento da soja, a massa de mil grãos consiste em um dos que sofre menor efeito do ambiente de produção e práticas de manejo, sendo fortemente influenciado pelo genótipo cultivado (RAMBO et al., 2004).

A cultivar Anta $82 \mathrm{RR}^{\circ}$ consistiu naquela que apresentou menor valor de massa de mil grãos. Apesar de sofrer menor influência do ambiente de produção quando comparado com os demais componentes de rendimento, a massa de mil grãos também é afetada em condições não favoráveis. Desta forma, o veranico ocorrido no experimento durante a fase de enchimento de grãos afetou todas as cultivares de soja, fato que pode ser percebido pela murcha do tecido foliar nas horas mais quentes do dia (Figura 1). A ocorrência do veranico, juntamente com a elevada população utilizada na semeadura da Anta $82 R^{\circ}$ pode ter resultado no aumento das perdas de massa de mil grãos para essa cultivar (WALKER et al., 2010).

A maior permanência no campo favoreceu as cultivares de soja mais tardias, tendo em vista que os materiais de ciclo maior apresentaram produtividade superior (NS 7670
$R R^{\circ}$ e $W 791 R R^{\circ}$ ) em detrimento àquelas de ciclo mais precoce (Tabela 4). Isso reforça a teoria de que a soja possui alta capacidade de modular seu crescimento de acordo com as condições de ambiente, tornando a produtividade de grãos pouco sensível às mudanças de espaçamento, fato já relatado em trabalhos previamente apresentados na literatura (GAN et al., 2002; HEIFFIG et al., 2006).

\section{Adensamento e épocas de semeadura (Safra 2015/16)}

Comparando o efeito dos dois fatores avaliados nos presentes experimentos, verifica-se que a época de semeadura teve maior influência nas variáveis-respostas do que o espaçamento entrelinhas utilizado (Tabela 5). Isto pode ser comprovado pelo número de vezes que foi verificada diferença significativa entre os tratamentos para cada fator avaliado, uma vez que, somando os resultados obtidos nos dois experimentos, observou-se dez variáveisrespostas sendo afetada pela época de semeadura, e apenas três pelo espaçamento entrelinhas. A única variável-resposta afetada pela interação da época de semeadura e espaçamento entrelinhas foi altura de plantas 
para o experimento realizado com a cultivar NA $5909 \mathrm{RR}^{\circ}$.

Tabela 5. Resumo da análise de variância (valores de $f$ calculado) de características morfológicas, componentes do rendimento e produtividade de grãos de dois genótipos de soja cultivados em diferentes épocas de cultivo e distribuição espacial de plantas. Rio Verde (GO), 2015/16

\begin{tabular}{|c|c|c|c|c|c|c|c|c|}
\hline \multirow{2}{*}{ Fontes de variação } & \multirow{2}{*}{ GL } & ALP & APV & RAM & NVP & NGV & MMG & PRO \\
\hline & & \multicolumn{7}{|c|}{--- NA 5909 RR ${ }^{\circ}$--- } \\
\hline Época & 2 & $7,4^{*}$ & $2,8^{\mathrm{ns}}$ & $4,9^{\text {ns }}$ & $0,8^{\text {ns }}$ & $93,0^{* *}$ & $140,3^{* *}$ & $4,3^{\mathrm{ns}}$ \\
\hline Erro 1 & 6 & - & - & - & - & - & - & - \\
\hline Espaçamento & 1 & $16,3^{* *}$ & $1,3^{\mathrm{ns}}$ & $0,01^{\mathrm{ns}}$ & $2,5^{\mathrm{ns}}$ & $6,0^{*}$ & $0,3^{\text {ns }}$ & $4,9^{\text {ns }}$ \\
\hline Época x Espaçamento & 2 & $8,1^{* *}$ & $0,2^{\text {ns }}$ & $1,2^{\mathrm{ns}}$ & $1,5^{\mathrm{ns}}$ & $0,5^{\mathrm{ns}}$ & $0,0^{\text {ns }}$ & $2,3^{\text {ns }}$ \\
\hline Erro 2 & 9 & - & - & - & - & - & - & - \\
\hline CV1 (\%) & & 6,1 & 10,9 & 19,9 & 7,1 & 3,5 & 2,1 & 8,1 \\
\hline \multirow[t]{2}{*}{ CV2 (\%) } & & 3,8 & 15,4 & 14,2 & 13,9 & 2,4 & 2,9 & 7,0 \\
\hline & & \multicolumn{7}{|c|}{--- M 7739 IPRO } \\
\hline Época & 2 & $111,8^{* *}$ & $15,2^{* *}$ & $9,2^{*}$ & $7,0^{*}$ & $30,0^{* *}$ & $125,3^{* *}$ & $10,6^{* *}$ \\
\hline Erro 1 & 6 & - & - & - & - & - & - & - \\
\hline Espaçamento & 1 & $3,0^{\text {ns }}$ & $1,2^{\mathrm{ns}}$ & $1,2^{\mathrm{ns}}$ & $8,0^{*}$ & $0,0^{\text {ns }}$ & $0,6^{\text {ns }}$ & $2,3^{\mathrm{ns}}$ \\
\hline Época x Espaçamento & 2 & $2,7^{\mathrm{ns}}$ & $0,9^{\text {ns }}$ & $2,0^{\text {ns }}$ & $1,4^{\mathrm{ns}}$ & $0,5^{\text {ns }}$ & $1,9^{\text {ns }}$ & $2,5^{\mathrm{ns}}$ \\
\hline Erro 2 & 9 & - & - & - & - & - & - & - \\
\hline CV1 (\%) & & 7,4 & 11,2 & 10,1 & 14,5 & 3,4 & 5,3 & 9,4 \\
\hline CV2 (\%) & & 7,2 & 13,0 & 13,5 & 13,6 & 3,9 & 3,9 & 9,8 \\
\hline
\end{tabular}

$\mathrm{ALP}=$ altura de plantas; $\mathrm{APV}=$ altura de inserção da primeira vagem; $\mathrm{RAM}=$ número de ramificações por planta; $\mathrm{NVP}=$ número de vagens por planta; $\mathrm{NGV}=$ número de grãos por vagem; $\mathrm{MMG}=$ massa de mil grãos; $\mathrm{PRO}=$ produtividade. ${ }^{\text {ns }}$ Não significativo. **, * Significativo a 1 e $5 \%$ de probabilidade pelo Teste de $F$, respectivamente.

A soja possui capacidade adaptativa a imposição de práticas de manejo diferenciadas, incluindo a semeadura adensada, podendo ser observado nessas condições modificações morfológicas nas plantas, as quais irão afetar não apenas os órgãos vegetativos, como também os componentes de rendimento da cultura (FERREIRA JÚNIOR et al., 2010). O fato de não ter sido observado efeito significativo da redução do espaçamento entrelinhas na maioria das variáveis-respostas avaliadas no presente trabalho não indica que essa prática de manejo não se fez interessante agronomicamente, tendo em vista que cada cultivar de soja pode se comportar de maneira distinta quando submetida a esta condição de semeadura. Faz se interessante a realização de novos estudos que avaliem a interação da redução do espaçamento entrelinhas com outras práticas de manejo, como a utilização de populações mais elevadas na semeadura e controle dos agentes bióticos (pragas, doenças e plantas daninhas) que interferem no desenvolvimento da cultura da soja.

A altura de plantas de soja foi influenciada de maneira semelhante pela época de semeadura em ambos os experimentos, uma vez que foi verificada tendência de se visualizar plantas mais altas com a realização da semeadura em épocas mais tardias (Tabela 6).

Para as duas cultivares, as plantas de soja com maiores alturas na ocasião da colheita foram encontradas nas parcelas com a semeadura realizada em 17 de novembro. Apesar do comportamento semelhante nas duas cultivares de soja para a variável altura de plantas, quando se compara a intensidade em que a mesma foi afetada pela época em que a semeadura foi realizada, nota-se uma distinção entre as cultivares, onde a NA 5909 RR $^{\circ}$ apresentou acréscimo na altura de plantas equivalente a $12 \%$ da primeira para terceira época de semeadura, enquanto que para a cultivar M 7739 IPRO ${ }^{\circ}$ este aumento ficou próximo de $75 \%$.

Ainda com relação à altura de plantas, no experimento realizado com a cultivar NA 5909 $R R^{\circ}$, verificou-se que as plantas de soja que foram semeadas no espaçamento entrelinhas adensado $(0,25 \mathrm{~cm})$, apresentavam maior estatura.

Apesar de não ser classificada como componente de rendimento da soja, a avaliação da altura de inserção da primeira vagem é importante, pois tem influência direta sobre a produtividade da cultura. Para essa avaliação, 
diferenças entre as épocas de semeadura da soja só foram observadas no experimento realizado com a cultivar M 7739 IPRO $^{\circ}$, sendo observado maiores valores de altura de inserção da primeira vagem com a semeadura realizada a partir de 02 de novembro (Tabela 6).

O número de ramificações e de vagens por planta não foi influenciado pelos diferentes tratamentos no experimento realizado com a cultivar NA $5909 \mathrm{RR}^{\circ}$ (Tabela 6). Para o experimento realizado com a cultivar M 7739
$\mathrm{IPRO}^{\circ}$, maiores números de ramificações e de vagens por planta foram observados nas parcelas em que a semeadura da soja foi realizada mais tardia (17 de novembro). Ainda para esta cultivar, verificou-se maior número de vagens por planta quando se procedeu a semeadura da soja em espaçamento entrelinhas adensado $(0,25 \mathrm{~cm})$, observando acréscimo de $16 \%$ neste componente de rendimento da soja.

Tabela 6. Altura de plantas, altura de inserção da primeira vagem, número de ramificações e de vagens por planta de soja cultivada em diferentes épocas e distribuição de plantas. Rio Verde (GO), 2015/16

\begin{tabular}{|c|c|c|c|c|c|c|}
\hline \multirow{3}{*}{ Épocas de semeadura } & \multicolumn{3}{|c|}{ NA $5909 R^{\circ}$} & \multicolumn{3}{|c|}{ M 7739 IPRO } \\
\hline & \multicolumn{6}{|c|}{--- Altura de plantas $(\mathrm{cm})$--- } \\
\hline & Tradicional & Adensado & Média & Tradicional & Adensado & Média \\
\hline 18 de outubro & 58,5 Aab* $^{*}$ & $57,6 \mathrm{Ab}$ & $58,0 \mathrm{~b}$ & 49,2 & 47,4 & $48,3 \mathrm{c}$ \\
\hline 02 de novembro & $55,8 \mathrm{Bb}$ & $64,2 \mathrm{Aa}$ & $60,0 \mathrm{ab}$ & 60,9 & 70,2 & $65,5 \mathrm{~b}$ \\
\hline 17 de novembro & $63,0 \mathrm{Ba}$ & $67,0 \mathrm{Aa}$ & 65,0 a & 83,6 & 86,3 & 84,9 a \\
\hline \multirow[t]{3}{*}{ Média } & $59,1 \mathrm{~B}$ & $62,9 \mathrm{~A}$ & & $64,5 \mathrm{~A}$ & $68,0 \mathrm{~A}$ & \\
\hline & \multicolumn{6}{|c|}{--- Altura de inserção da primeira vagem $(\mathrm{cm})$--- } \\
\hline & Tradicional & Adensado & Média & Tradicional & Adensado & Média \\
\hline 18 de outubro & 12,7 & 12,4 & $12,5 \mathrm{a}$ & 14,2 & 11,9 & $13,1 \mathrm{~b}$ \\
\hline 02 de novembro & 14,9 & 13,5 & $14,2 \mathrm{a}$ & 16,4 & 16,8 & $16,6 \mathrm{a}$ \\
\hline 17 de novembro & 14,4 & 13,2 & $13,8 \mathrm{a}$ & 18,2 & 17,4 & $17,8 \mathrm{a}$ \\
\hline \multirow[t]{3}{*}{ Média } & $14,0 \mathrm{~A}$ & $13,0 \mathrm{~A}$ & & $16,3 \mathrm{~A}$ & $15,4 \mathrm{~A}$ & \\
\hline & \multicolumn{6}{|c|}{--- Número de ramificações --- } \\
\hline & Tradicional & Adensado & Média & Tradicional & Adensado & Média \\
\hline 18 de outubro & 5,3 & 5,0 & $5,1 \mathrm{a}$ & 7,7 & 7,5 & $7,6 a b$ \\
\hline 02 de novembro & 3,7 & 4,3 & $4,0 \mathrm{a}$ & 7,1 & 7,2 & $7,1 \mathrm{~b}$ \\
\hline 17 de novembro & 4,1 & 3,8 & 3,9 a & 8,0 & 9,6 & $8,8 \mathrm{a}$ \\
\hline \multirow[t]{3}{*}{ Média } & $4,4 \mathrm{~A}$ & $4,4 \mathrm{~A}$ & & $7,6 \mathrm{~A}$ & $8,1 \mathrm{~A}$ & \\
\hline & \multicolumn{6}{|c|}{--- Número de vagens por planta --- } \\
\hline & Tradicional & Adensado & Média & Tradicional & Adensado & Média \\
\hline 18 de outubro & 33,8 & 38,0 & 35,9 a & 51,7 & 56,7 & $54,2 \mathrm{~b}$ \\
\hline 02 de novembro & 33,8 & 41,1 & $37,5 \mathrm{a}$ & 55,0 & 61,0 & $58,0 a b$ \\
\hline 17 de novembro & 37,2 & 35,6 & $36,4 \mathrm{a}$ & 61,1 & 78,5 & 69,8 a \\
\hline Média & $34,9 \mathrm{~A}$ & $38,2 \mathrm{~A}$ & & $55,9 \mathrm{~B}$ & $65,4 \mathrm{~A}$ & \\
\hline
\end{tabular}

* Médias seguidas de mesma letra, minúscula na coluna e maiúscula na linha, para cada cultivar, não diferem entre si pelo teste de Tukey a $5 \%$.

Komatsu et al. (2010) observaram que a soja semeada no espaçamento de $0,17 \mathrm{~m}$ apresentou maior quantidade de vagens por planta quando comparado com a semeadura realizada adotando espaçamento $0,45 \mathrm{~m}$. Segundo esses autores o adensamento da soja proporciona menor competição intraespecífica, por isso as plantas apresentam maiores números de vagens.

Para ambos os experimentos, observouse maior número de grãos por vagem à medida que a época de semeadura da soja foi postergada, registrando-se os maiores valores com a semeadura realizada a partir de 02 e 17 de novembro, respectivamente, para as cultivares NA 5909 RR $^{\circ}$ e M 7739 IPRO $^{\circ}$ (Tabela 7). Diferenças entre o espaçamento entrelinhas utilizado na semeadura da soja para a variável número de grãos por vagem só foram observadas na cultivar NA $5909 \mathrm{RR}^{\circ}$, registrando-se superioridade com a utilização de espaçamento adensado $(0,25 \mathrm{~m})$. 
Não foi observada influência do espaçamento entrelinhas da soja sobre a massa de mil grãos (Tabela 7). Diferentemente do observado para os outros componentes de rendimento da cultura, essa variável-resposta reduziu à medida que a semeadura da soja foi realizada mais tardiamente, sendo 0 comportamento relatado semelhante nos dois experimentos. Komatsu et al. (2010) demonstraram anteriormente que a redução no espaçamento de semeadura da soja interferiu negativamente sobre a massa de mil grãos de algumas cultivares.

Tabela 7. Número de grãos por vagem, massa de mil grãos e produtividade de soja cultivada em diferentes épocas e distribuição de plantas. Rio Verde (GO), 2015/16

\begin{tabular}{|c|c|c|c|c|c|c|}
\hline \multirow{3}{*}{ Épocas de semeadura } & \multicolumn{3}{|c|}{ NA $5909 R^{\circ}$} & \multicolumn{2}{|c|}{ M 7739 IPRO $^{\circ}$} & \multirow[b]{3}{*}{ Média } \\
\hline & \multicolumn{5}{|c|}{--- Número de grãos por vagem --- } & \\
\hline & Tradicional & Adensado & Média & Tradicional & Adensado & \\
\hline 18 de outubro & 1,8 & 1,9 & $1,8 b^{*}$ & 2,0 & 2,0 & $2,0 \mathrm{c}$ \\
\hline 02 de novembro & 2,3 & 2,3 & $2,3 \mathrm{a}$ & 2,2 & 2,1 & $2,2 \mathrm{~b}$ \\
\hline 17 de novembro & 2,2 & 2,2 & $2,2 \mathrm{a}$ & 2,3 & 2,3 & $2,3 \mathrm{a}$ \\
\hline \multirow[t]{3}{*}{ Média } & $2,0 \mathrm{~B}$ & $2,1 \mathrm{~A}$ & & $2,1 \mathrm{~A}$ & $2,1 \mathrm{~A}$ & \\
\hline & \multicolumn{6}{|c|}{--- Massa de mil grãos (g) --- } \\
\hline & Tradicional & Adensado & Média & Tradicional & Adensado & Média \\
\hline 18 de outubro & 184 & 183 & $184 \mathrm{a}$ & 205 & 202 & $204 a$ \\
\hline 02 de novembro & 165 & 163 & $164 \mathrm{~b}$ & 178 & 188 & $183 \mathrm{~b}$ \\
\hline 17 de novembro & 154 & 154 & $154 \mathrm{c}$ & 134 & 133 & $134 \mathrm{c}$ \\
\hline \multirow[t]{3}{*}{ Média } & $167 \mathrm{~A}$ & $166 \mathrm{~A}$ & & $172 \mathrm{~A}$ & $174 \mathrm{~A}$ & \\
\hline & \multicolumn{6}{|c|}{--- Produtividade $\left(\mathrm{kg} \mathrm{ha}^{-1}\right)$--- } \\
\hline & Tradicional & Adensado & Média & Tradicional & Adensado & Média \\
\hline 18 de outubro & 4500 & 4506 & $4503 \mathrm{a}$ & 5903 & 5571 & $5737 a$ \\
\hline 02 de novembro & 4622 & 5295 & 4958 a & 5646 & 6122 & $5884 \mathrm{a}$ \\
\hline 17 de novembro & 4371 & 4563 & 4467 a & 4372 & 5219 & $4796 \mathrm{~b}$ \\
\hline Média & $4497 \mathrm{~A}$ & $4788 \mathrm{~A}$ & & $5307 \mathrm{~A}$ & $5637 \mathrm{~A}$ & \\
\hline
\end{tabular}

* Médias seguidas de mesma letra, minúscula na coluna e maiúscula na linha, para cada cultivar, não diferem entre si pelo teste de Tukey a $5 \%$.

A produtividade da soja só foi afetada pelos tratamentos no experimento realizado com a cultivar M 7739 IPRO $^{\circ}$, sendo registrado o menor rendimento de grãos com a semeadura realizada em 17 de novembro, em comparação com as outras épocas (Tabela 7). Nota-se que para essa cultivar, o atraso na época de semeadura afeta negativamente $o$ potencial produtivo da soja.

Ao relacionar os resultados dos componentes de rendimento com a produtividade observada em ambas as cultivares avaliadas nos experimentos, verifica-se que há efeito compensatório entre os mesmos, tendo em vista que se por um lado houve acréscimo no número de vagens por planta e de grãos por vagem, por outro lado há diminuição na massa de grãos da soja com a realização da semeadura em épocas mais tardias. De certa forma, o comportamento citado pode servir de explicação para o fato de não ter sido constatada diferenças na produtividade da cultivar NA $5909 \mathrm{RR}^{\circ}$ entre épocas de semeadura.

Por outro lado, para a cultivar M 7739 IPRO $^{\circ}$, o efeito negativo que o atraso na época de semeadura exerceu sobre a variável massa de mil grãos foi tão pronunciado, que este acabou refletindo na produtividade da soja. Em ambos os experimentos, não houve influência da redução do espaçamento entrelinhas de semeadura na produtividade da cultura da soja.

Apesar de não ter sido verificada influência da redução de espaçamento entrelinhas sobre a produtividade da soja, é importante destacar que não existe um espaçamento e uma densidade de plantas ideal para todos os ambientes e cultivares, sendo relevante a observação da interação entre o espaçamento e densidade de plantas para cada condição de cultivo (CALISKAN et al., 2007). Desta forma, é necessário a realização de estudos que visem identificar para quais ambientes e cultivares de soja é interessante a adoção desta 
prática, pois com essas informações será possível agrupar genótipos que respondem ou não à redução do espaçamento, otimizando o potencial de cada cultivar.

\section{CONCLUSÕES}

As cultivares de soja apresentam distintas características de desenvolvimento e produtividade. De maneira geral, as cultivares de hábito de crescimento indeterminado e ciclo tardio apresentam-se como mais produtivas.

A semeadura da soja em espaçamento entrelinhas tradicional $(0,5 \mathrm{~m})$ ou adensado $(0,25$ $\mathrm{m})$ se equivale, não sendo observadas diferenças de produtividade da cultura. A semeadura da soja realizada mais tardiamente apresenta efeito negativo sobre a produtividade.

\section{REFERÊNCIAS}

ALMEIDA, R.D.; PELUZIO, J.M.; AFFÉRRI, F.S. Divergência genética entre cultivares de soja, sob condições de várzea irrigada, no sul do Estado Tocantins. Revista Ciência Agronômica, v.42, n.1, p.108-115,

2011.

http://dx.doi.org/10.1590/S1806-

$\underline{66902011000100014}$

BALBINOT JUNIOR, A.A. Acamamento de plantas na cultura da soja. Agropecuária Catarinense, v.25, n.1, p.40-43, 2011.

BALBINOT JUNIOR, A.A.; PROCÓPIO, S.O.; DEBIASI, H.; FRANCHINI, J.C. Densidade de plantas na cultura da soja. Londrina: Embrapa Soja, 2015. 36 p.

CALISKAN, S.; ARSLAN, M.; ÜREM, I.; CALISKAN, M.E. The effects of row spacing on yield and yield components of full season and double-cropped soybean. Turkish Journal of Agriculture and Forestry, v.31, n.3, p.147-154, 2007.

COX, W.J.; CHERNEY, J.H. Growth and yield responses of soybean to row spacing and seeding rate. Agronomy Journal, v.103, n.1, p.123-128, 2011.

\section{http://dx.doi.org/10.2134/agronj2010.0316}

DUTRA, L.M.C. et al. População de plantas em soja. In. REUNIÃO DE PESQUISA DE SOJA DA REGIÃO SUL, 35., 2007, Santa Maria, RS. Anais... Santa Maria: Universidade Federal de Santa Maria, 2007. p.95.
EMBRAPA. Centro Nacional de Pesquisa de Solos. Sistema Brasileiro de Classificação de Solos. 3. ed. Rio de Janeiro: Embrapa Solos, 2013. 353 p.

FERREIRA JÚNIOR, J. A.; ESPÍNDOLA, S. M. C. G.; GONÇALVES, D. A. R.; LOPES, E. W. Avaliação de genótipos de soja em diferentes épocas de plantio e densidade de semeadura no município de Uberaba-MG. Fazu em Revista, v.7, n.1, p.1321, 2010.

FERREIRA, D.F. Sisvar: a computer statistical analysis system. Ciência e Agrotecnologia, v.35, n.6, p.1039-1042, 2011. http://dx.doi.org/10.1590/S141370542011000600001

GAN, Y.; STULENA, I.; KEULENC, H. V.; KUIPERA, P. J. C. Physiological response of soybean to plant density. Field Crops Research, v.74, n.2-3, p.231241, 2002. https://doi.org/10.1016/S03784290(01)00212-X

HEIFFIG, L. S.; CÂMARA, G. M. S.; MARQUES, L. A.; PEDROSO, D. B.; PIEDADE, S. M. S. Fechamento e índice de área foliar da cultura da soja em diferentes arranjos espaciais. Bragantia, v.65, n.2, p.285-295, 2006.

http://dx.doi.org/10.1590/S0006$\underline{87052006000200010}$

KOMATSU, R. A.; GUADAGNIN, D. D.; BORGO, M. A. Efeito do espaçamento de plantas sobre o comportamento de cultivares de soja de crescimento determinado. Campo Digit@।, v.5, n.1, p.50-55, 2010.

LIMA, S. F. ALVAREZ, R. C. F.; THEODORO, G. F.; BAVARESCO, M.; SILVA, K. S. Efeito da semeadura em linhas cruzadas sobre a produtividade de grãos e a severidade da ferrugem asiática da soja. Bioscience Journal, v.28, n.6, p.954-962, 2012.

MAUAD, M.; SILVA, T. H. B.; ALMEIDA NETO, A. I.; ABREU, V. G. Influência da densidade de semeadura sobre características agronômicas na cultura da soja. Revista Agrarian, v.3, n.9, p.175$181,2010$.

MUNDSTOCK, C. M; THOMAS, A. L. Soja: fatores que afetam o crescimento e o rendimento de grãos. Porto Alegre: Departamento de plantas de lavoura da UFRGS: Evangraf, 2005. 
NAVARRO JÚNIOR, H. M.; COSTA, J. A. Contribuição relativa dos componentes do rendimento para produção de grãos em soja. Pesquisa Agropecuária Brasileira, v.37, n.3, p.269-274, 2002.

http://dx.doi.org/10.1590/S0100-

\section{X2002000300006}

PEIXOTO, C. P.; SOUSA, C. G. M.; CAGNIN, M. M.; MATTIAZZI, P. Épocas de semeadura e densidade de plantas de soja: I. Componentes da produção e rendimento de grãos. Scientia Agrícola, v.57, n.1, p.89-96, 2000. http://dx.doi.org/10.1590/S0103$\underline{90162000000100015}$

PELUZIO, J. M.; VAZ-DE-MELO, A.; COLOMBO, G. A.; SILVA, R. B.; AFFÉRRI, F. S.; PIRES, L. P. M.; BARROS, H. B. Efeito da época e densidade de semeadura na produtividade de grãos de soja na Região Centro-Sul do estado do Tocantins. Pesquisa Aplicada e Agrotecnologia, v.3, n.3, p.145-153, 2010.

PRICINOTTO, L. F.; ZUCARELI, C. Paclobutrazol no crescimento e desempenho produtivo da soja sob diferentes densidades de semeadura. Revista Caatinga, v.27, n.4, p.65-74, 2014.

PROCÓPIO, S. O.; BALBINOT JUNIOR, A. A.; DEBIASI, H.; FRANCHINI, J. C.; PANISON, F. Semeadura em fileira dupla e espaçamento reduzido na cultura da soja. Revista Agro@mbiente On-line, v.8, n.2, p.212-221, 2014.

RAMBO, L.; COSTA, J. A.; PIRES, J. L. F.; PARCIANELLO, G.; FERREIRA, F.G. Estimativa do potencial de rendimento por estrato do dossel da soja, em diferentes arranjos de plantas. Ciência Rural, v.34, n.1, p.33-40, 2004. http://dx.doi.org/10.1590/s0103-

$\underline{84782004000100006}$

SILVA, E.C.; FERREIRA, D.F.; BEARZOTI, E. Avaliação do poder e taxas de erro tipo i do teste de Scott-Knott por meio do método de Monte Carlo. Ciência e Agrotecnologia, v.23, n.3, p.687696, 1999.

SILVA, W.B.; PETTER, F.A.; LIMA, L.B.; ANDRADE, F.R. Desenvolvimento inicial de Urochloa ruziziensis e desempenho agronômico da soja em diferentes arranjos espaciais no Cerrado Mato-
Grossense. Bragantia, v.72, n.2, p.146-153, 2013. http://dx.doi.org/10.1590/S0006$\underline{87052013000200006}$

SUBEDI, K.D.; MA, B.L.; XUE, A.G. Planting date and nitrogen effects on grain yield and protein content of spring wheat. Crop Science, v.47, n.1, p.36-47, 2007. http://dx.doi.org/10.2135/cropsci2006.02.0099

WALKER, E.R.; MENGISTU, A.; BELLALOUI, N.; KOGER, C.H.; ROBERTS, R.K.; LARSON, J.A. Plant population and row-spacing effects on maturity group III soybean. Agronomy Journal, v.102, n.3, p.821-826, 2010. http://dx.doi.org/10.2134/agroni2009.0219

Recebido para publicação em 19/10/2017 Revisado em 10/04/2018

Aceito em 28/06/2018 